\title{
The Need of Distance Learning in the Wake of COVID-19 in Morocco:
} Teachers' Attitudes and Challenges in the EFL Instruction

\author{
Bachiri Housseine \\ The Euromed University of Fes, Morocco \\ h.bachiri@ueuromed.org \\ Sahli Rabha \\ Moulay Tayeb El Alaoui High School, Morocco \\ sahlirabha80@gmail.com
}

DOI: http://doi.org/10.36892/ijlls.v2i3.326

\begin{tabular}{|c|c|}
\hline $\begin{array}{l}\text { Received: } \\
\text { 10/06/2020 }\end{array}$ & $\begin{array}{l}\text { Abstract } \\
\text { Owing to the rapidly ubiquitous infection of Coronavirus in Morocco and }\end{array}$ \\
\hline $\begin{array}{l}\text { Accepted: } \\
\text { 16/09/2020 }\end{array}$ & $\begin{array}{l}\text { other parts of the globe, a plethora of governments have urgently resorted } \\
\text { to implement distance learning to save the current academic year from an } \\
\text { evitable failure. Given the non-prevalence of information and } \\
\text { communication technologies (ICTs) in Morocco, distance learning has been }\end{array}$ \\
\hline $\begin{array}{l}\text { Keywords: } \\
\text { Distance Learning; } \\
\text { ICTs; Attitudes; } \\
\text { Challenges; } \\
\text { Multimedia-Based } \\
\text { Education }\end{array}$ & $\begin{array}{l}\text { a quite bold attempt to officially continue education, even after the closure } \\
\text { of schools and campuses, without interruption with a slightly adjusted } \\
\text { grading scale in order to lead the boat of the current academic year to a } \\
\text { safe harbor. In this regard, many underprivileged students have benefitted } \\
\text { from free modems and laptops, the case of Euromed University of Fes } \\
\text { (UEMF). This great initiative has enabled the aforementioned students to } \\
\text { enjoy the full experience of distance learning. As for secondary schools and } \\
\text { most public institutions, the supply of electronic devices has almost been } \\
\text { lacking. One should know that the government has taken some modest } \\
\text { initiatives, such as offering free access to a few platforms, national } \\
\text { channels, and official pages of the aforesaid ministry, namely TelmidTICE. } \\
\text { It must be noted that distance learning, in Morocco, has continuously } \\
\text { undergone various challenges during COVID-19 ranging from content and } \\
\text { pedagogy to assessment and evaluation. Having used both quantitative and } \\
\text { qualitative research for the purpose of gathering relevant data by means of } \\
\text { questionnaire and participant observation, we have been able to ferret out } \\
\text { the real challenges that are structurally embedded and ramified in the } \\
\text { application of distance learning whose infrastructure must be constantly } \\
\text { buttressed via empirical research and quality teacher training to better } \\
\text { respond to different learning needs and styles, and simultaneously combat } \\
\text { digital illiteracy. }\end{array}$ \\
\hline
\end{tabular}

1. INTRODUCTION

This article primarily endeavors to theoretically and empirically investigate distance learning in the EFL instruction in Morocco from a pedagogical standpoint. Likewise, it attempts to unpack the attitudes and challenges perpetually encountered by Moroccan teachers. It must be noted that distance learning has unexpectedly coincided with the outbreak of COVID-19, which has made its usage an inescapable reality in the field of education as a whole as it were. Therefore, the government has called upon private and public stakeholders to combine their efforts to facilitate the application of this new paradigm of learning through the use of information and communication technologies (ICTs) in order to enable students to follow their courses from home. Thus, teachers have to adapt their skills and develop new 
competencies in order to qualitatively perform their educational tasks, and systematically integrate ICTs into their teaching practice and philosophy (Simin et al. 2016).

The decision of distance learning has strongly been endorsed by the Ministry of National Education and Vocational Training (Ministry of Education 2020) after the closure of educational institutions and research centers in the Kingdom and was repeatedly discussed in the Moroccan Parliament and the House of Representatives in order to swiftly respond to the rising demands of distance learning during this pandemic era. Given the unfamiliarity of the majority of Moroccan EFL instructors with distance learning alongside the insufficient amount of literature pertinent to the Moroccan context, this study aspires to explore in practical manners the application of distance learning during COVID-19, primarily in the EFL classroom.

This unprecedented technological experience is meant to benefit students with quality learning and training at all levels, and at the same time save the academic year from a doomed failure. Given the unreadiness of a gazillion of Moroccan teachers, digitally illiterate, to embark upon this emergent digital endeavor, such a holistic and diverse e-learning process ought to endure certain shortcomings, essentially its application and practicality in the long run.

The current pandemic, COVID-19, has increasingly and widely ignited a rapid implementation of ICTs, hence sparking a national debate over its repercussions among researchers, EFL practitioners and learners, and TEFL instructors, particularly in certain remote and precarious areas that lack both electricity and internet access. By necessity, distance learning has unceremoniously declared itself to become an indispensable teaching/learning process for the time being. In actuality, both teachers and learners are both called upon to computerize and digitalize their educational input/output via various online platforms, such as Microsoft Teams, Zoom, Google Classroom, Moodle, and so forth, which necessitates the use of communication devices, such as smartphones, computers, tablets, and others alike. In order to deepen and extend the merits of distance learning, teachers tend to do an immense amount of course preparation, such as facilitating the teaching materials with written annotations, explanation, and elaboration. Such materials are sent out in advance, along with designing a variety of activities to accommodate students' learning styles and multiple intelligences. This way students feel comfortable and ready for the learning exchange in the virtual classroom to follow with clarity and purpose. In so doing, they simultaneously enrich, by exemplification, the input delivered by the teacher, especially if the activity is fluency-oriented.

In effect, we do not know for a fact whether distance learning under the current circumstances will be able to reach its intended effects and merits, for it has not yet been assessed and evaluated by expert TEFL practitioners and educators in Morocco in order to measure how far students have gone with distance learning in the wake of COVID-19. Therefore, as with any other educational approach and/or program, face-to-face or virtual, it is of paramount importance that distance learning must undertake a painstaking evaluation so as to pinpoint its strengths and weaknesses. "When the evaluation is done, we can hope that the results are positive and gratifying, both for those responsible for the program and for upper-level managers who will make decisions based on their evaluation of the program" (Kirkpatrick \& Kirkpatrick 2006, p. 3). Given the unexpected implementation of distance learning, the Ministry of National Education and Vocational Training has not, in fact, conducted an authentic impact assessment on students at all academic levels, given the different learning styles. As a matter of fact, the aforementioned ministry should have at least administered a needs analysis so as to ferret out its resilience, efficacy, and appropriateness among both teachers and learners who are the main and direct beneficiaries and stakeholders. 
The bottom-up approach will closely bring us to the general framework of distance learning, and simultaneously disclose a plethora of realities, and specifically lift the ban on the teacher-student relationship in the virtual EFL classroom. Furthermore, the current study will blatantly help establish a profound understanding of distance learning, and at the same time systematically unravel the attitudes and challenges faced by teachers.

This study is divided into five parts. The first part is devoted to the introduction, which attempts to provide a broad picture of how Morocco resorted to distance learning in the wake of COVID-19 as an emergent approach/program to prevent interruption of any sort in the current academic year, as well as investigate the challenges of the distance learning application. The second part is dedicated to related work which succinctly reviews relevant and up-to-date literature on distance learning and the challenges it comes with it. The third part presents the methodology adopted, namely the research sample, design, and instrumentation. The fourth part deals with data analysis and discussion. Finally, part 5 entails the conclusion and further work.

\section{LITERATURE REVIEW}

There is no doubt that distance learning offers plenty of benefits to educators and learners. It is a powerful tool that can incrementally weave change into education, as well as create empowering partnerships with multi-stakeholders to better cope with the increasingly rising learning demands in the wake of COVID-19. In fact, distance learning can be a locomotive to upgrade and bolster the quality of teaching/learning, hence taking Morocco's education system to a whole new digitalized world of information and knowledge, while simultaneously mitigating the loss of education. More specifically, it brings about a wide range of benefits to serve the art of teaching, mainly content and pedagogy at large. Belanger and Jordan (2000) both assert that distance education increases flexibility, access to the learning, choice of institution, access to remote experts, performance, compensation, better marketability, and lifelong learning opportunities.

To respond to the sudden implementation of distance learning, the Ministry of National Education and Vocational Training, in Morocco, has strived to orient national channels toward educational content-based programs and offer useful platforms, such as TelmidTICE where diverse digital educational content is delivered. However, although distance learning offers a wide range of opportunities to sustain education, there still exists a multitude of obstacles that hamper its merits. Additionally, numerous scholars and educators have debated the conceptual framework of distance learning. In this regard, Sadeghi (2019) maintained that there is no sole theory or an effective approach to operate distance education, and according to Picianno (2017), many theories were driven from previously tackled theories. Bouziane (2019) contends that virtual learning is not seriously taken by decision-makers as its infrastructure is flimsy, which unequivocally portrays a cloudy strategic vision in the field of education. Within this framework, the National Charter of Education and Training (1999), mainly Article 10 of the Charter emphasizes the integration of ICT in education, as well as enhancing students' familiarization, interaction and adoption of different multimedia-based learning platforms, through GENIE that was launched by his majesty King Mohammed VI on September 15, 2005. This initial three-year program was subsequently extended attempting to improve the quality of teaching/learning in Morocco through digitalization, multimedia training and research in partnership with the U.S. Agency for International Development (USAID). Interestingly, there was another e-learning training program that followed, namely Improving Training for Quality Advancement in National Education (ITQANE) that primarily sought to provide distance learning and training to teachers, while enhancing educational engineering, instructional technology, and online tutoring. This impeccable initiative gave birth to a new training program bearing the name of Internet-Based Training 
Network for Quality in Education (RAFIQE). The latter was accomplished in collaboration with the previously selected training participants in ITQANE. Given this, one should stress that there must be a true marriage between not only technology and course content but also pedagogy, which seems to have the potency to change the classroom dynamics in the EFL instruction for the benefit of students.

Nachit et al. (2013) brought up the issue of ICT training in Moroccan schools, which is insufficient by all means as a big number of teachers conspicuously lack the skills needed when integrating ICT into the classroom. They have poor training with respect to the use of interactive boards, ICT-based teaching software and materials, webinars, educational platforms, and so forth. This shaky foundation and reluctance, if not unreadiness, of the aforementioned teachers, continue to gradually weaken and minimize the harvest of distance learning in the EFL classroom. Ostensibly, we cannot put the blame on teachers solely for their unreadiness or lack of preparation to embark upon the integration of ICT to fuel distance learning, since there is another problem, of a technical nature, related to the scarcity of internet access in most schools and homes in Morocco. This stands as an existential hurdle, which constantly does not permit the fruits of distance learning to ripen up, hence making it a far-fetched endeavor in the worst-case scenario.

Kirkwood investigated how undergraduate learners use online resources. He explains that most learners use the internet for "personal, domestic, social and employment purposes as well as for educational goals" (2008, p 381), but looking for information resources is most common when it is inextricably linked to their studies, particularly in relation with the assessment.

Brand stressed, "If students are going to be prepared for a technological society, they must be taught by confident and skilled teachers. This can only be done by adequate training and development of teachers" (1998, p. 13). In the same manner, Jones (2004) came up with seven barriers that affect the integration of ICT into teaching. These barriers are lack of confidence among teachers during integration, access resources, time for the integration, effective training facing technical problems in use, personal access during lesson preparation, age of the teachers, and teaching experiences. Similarly, according to Becta (2004), there are two main groups of barriers, namely the individual and the institution. For the former, it is lack of confidence and time, as well as being resistant to change. For the latter, it is lack of teacher's training on ICT and access to resources.

Mumtaz (2000) states that 'teachers' beliefs about teaching and learning with ICT are central to integration". In other words, if teachers hold positive attitudes toward the implementation of technologies they are more likely to change their outlook about the adoption of ICT into teaching. For Hutchison and Reinking (2011), a lack of specific knowledge about technology and how to combine it with the existing pedagogical content knowledge might be inefficient to support students' learning.

The TPACK framework emphasizes "the connections among technologies, curriculum content, and specific pedagogical approaches"; it is expected to demonstrate 'how teachers' understandings of technology, pedagogy, and content can interact with one another to produce effective discipline-based teaching with educational technologies" (Harris et al. 2009, p. 396).

Professor Fouzia Messoudi (2012) conducted a detailed study about ICT and its infrastructure in both public and private schools in Morocco where she investigated strategies, visions, challenges, and programs. She aspired to explore and evaluate the merits and impacts of the use of ICT on education and the reception of it on the part of both teachers and learners. Unfortunately, certain subjects, such as chemistry, biology, fluid mechanics, and mathematics whose nature is highly technical or lab-based, and hence require experimentation, analysis, or calculation can potentially be very demanding and labourintensive. This might make the intended impact on discombobulating and disorienting. 
Although many educators and TEFL instructors triumph and romanticize their interaction with distance learning, the issue of quality pedagogy, at its core, poses myriad obstacles.

\section{METHODOLOGY}

The paper under study is conducted by the use of quantitative and qualitative methods. It aims at yielding bona fide data by dint of a teacher-based questionnaire and class observation, using two different platforms (Microsoft Teams and WhatsApp). The latter has been used by EFL teachers to deliver digital input when they unanticipatedly shifted from traditional class education to distance learning after the outbreak of the Coronavirus pandemic. The rationale of embracing a mixed-methods approach lies in the tendency to empirically evaluate distance learning in the teaching/learning process, and explore the sample's attitudes, perceptions and challenges while delivering digital content. Thus, this research has definitely generated a numerical measurement and an in-depth exploration of the participants' dynamics. The sections below entail research participants and questionnaire distribution, along with participant observation, which is divided into two subsections

\subsection{Research participants and questionnaire distribution}

To collect relevant data for our study, we used the questionnaire as the first most important instrument in order to yield statistical information about distance learning in the wake of COVID-19. The questionnaire was administered online through Google Forms. The sample consisted of 50 participants, English teachers, of different age groups. Males formed $64 \%$, while females $36 \%$, making the participation of males largely higher than that of females. It must be noted that the gender variable is not an issue, and hence will not be taken into consideration in the analysis of this particular study.

The research sample was randomly selected. The link of the questionnaire was electronically sent to numerous English teachers in Morocco teaching in different schools and institutions either via email or social media, namely Facebook Messenger, Facebook Groups, and WhatsApp.

The design of the questionnaire was driven by the inclination to generate authentic data for our current study. More importantly, the questionnaire specifically comprised of 10 questions. There were 7 close-ended questions and 3 open-ended questions. The latter was particularly banked on both the attitudes that English teachers hold toward distance learning in the EFL instruction, along with the challenges they undergo when digitally delivering educational input.

To ensure maximum face validity, a pilot study was carried out in order to evaluate the feasibility, soundness, and relevance of the questionnaire's content. The questionnaire was initially distributed to 10 English teachers to mark or cross out any questions that were verbose, ambiguous, or unfathomable. Afterwards, the aforementioned teachers were instructed to provide feedback about the layout and length of the questionnaire. Once the pilot test finished, the researchers embarked on modifying and amending the questionnaire, and then it was ipso facto sent out to participants via Google Forms.

\section{DATA ANALYSIS AND DISCUSSION 4.1 Participant Observation}

The use of qualitative research was strategically chosen to be the second most important instrument to gather direct data from the teaching environment in order to clearly fathom out the nature and dynamics of distance learning while emphasizing teachers' attitudes and the challenges they faced in this transition (moving from traditional teaching to online teaching). 
Since March $16^{\text {th }}, 2020$, and after the closure of all schools and institutes, followed by the announcement of the emergency case in all parts of Morocco, decision-makers and all active practitioners competed not only to create digital content for their students but also to choose the best platforms to deliver this input in an attempt to reach the satisfaction they used to experience in face-to-face teaching. As a matter of fact, a great number of teachers were exposed to distance learning for the first time because they were obliged to select the most convenient platform(s) in order to measure up to students' expectations in the wake of Coronavirus pandemic. This disclosure should not drive us to over-generalize because there was a great number of English teachers who have been striving to equip themselves with all the necessary technology skills and seek to create enticing digital courses to attain their pedagogical objectives. That is why, one of the instruments employed in this study was the participant observation that has been running by us, EFL instructors, since the mid of March 2020.

In the subsections below (3.2.1 and 3.2.2), the researchers will provide personal accounts of their current experiences with distance learning by use of two different platforms, Microsoft teams and WhatsApp, in their virtual EFL classrooms. The observations have been both different and substantial, especially with respect to class size, activities (fluency or accuracy oriented)), location (Fes and Salé), duration, and most importantly pedagogy.

\subsubsection{Distance Learning Via Microsoft Teams}

At the Euromed University of Fes, all professors have been using Microsoft Teams as the only official educational platform across all academic disciplines, such as architecture, business, engineering, computer science, communication and tourism studies, and so on. Both engineers and technicians in the Information Technology department summoned up their efforts and utilized both research and practical experience to facilitate this transition. An explanatory image-based document and a step-by-step tutorial were sent out to professors to clarify and simplify the installing initial steps. Ultimately, this operation was carried out successfully.

The period of participant observation with regard to the online teaching of English began on March 16, 2020, and ended toward the end of May 2020. It was done once a day during business days. The duration of each class was 2 hours, but as the month of Ramadan approached it was reduced to 1 hour and a half. I should emphasize that prior to Ramadan, distance learning was gradually adopted. New students were invited to join the platform, and those who were not familiar with the procedure were added by the administration, using their university email addresses. Once all students were on the platform, we began interacting visually. Some students were bashful, and hence they did not turn on the camera, while others did. In fact, the ones who did make distance learning even more communicative and visually invigorating and immersive as we could see each other from different parts of Morocco. Naturally, the implementation of distance learning was a bit slow as students were at the phase of discovering how to operate the platform and efficiently use its virtual learning tools, such as sending a text message, muting the microphone, attaching documents, screen sharing when they had to deliver presentations, and so forth. As an EFL teacher, I felt comfortable with the use of Microsoft Teams. I used different instructional tools to accommodate different ability levels and learning styles. I heavily relied on participatory and student-centred approaches, which seemed to incrementally improve the quality of distance learning and engendered a sense of inclusion for all students.

The warm-up and previous class review was done at the beginning of each session piqued the interest of the students, and thus gradually accentuated and rejuvenated their engagement and participation. More specifically, the warm-up was tantamount to therapy as students succinctly spoke about how they spent their time at home, and also the kind of 
activities they did. For them, it was a relieving feeling as they had someone to listen to them and relate to them as well. At the human level, this moral support was psychologically useful to their mental health during COVID-19.

I always made sure to send the course content before class time, and this created a positive atmosphere in the virtual classroom. Students were prepared with extensive questions and seamlessly communicated new thoughts and perspectives in nearly every class session. There was no break in class as students were actively engaged while being home. As time went by, I had to divide students into small groups to do collective work, such as miniresearch projects, dialogues, presentations, summaries, etc. This required them to work online even after the end of class. As a researcher and observer, I was frequently asking them about their work methodology. These questions revealed that even though they missed face-to-face teaching, given my gregarious and outgoing nature, they quite enjoyed distance learning, especially it was a relaxed atmosphere. It also revealed that the majority of students preferred being connected to the internet while studying, and this allowed them to define and further research the issue or theme being discussed in the EFL virtual classroom without constantly asking questions about dictionary meanings of words.

My participant observation was conducted through the courses I taught in the second semester, such as extensive reading, research methodology, Euromed culture, advanced grammar, and academic writing. Given the diversity of the aforementioned courses, the venture into distance learning was met with great success for both the students and myself with few omnipresent challenges, especially at the technical and organizational levels.

As in most classes I taught, there was a large number of students ranging from 20 to 30 maximum. In fact, a large number of participants in these classes somehow weakened the educational effects of certain activities, mainly role plays and interactive demonstrations. With the coming of Ramadan, many students connected to class late and their commitment and engagement level decreased dramatically, which led to half-hearted or poor participation. In the same vein, it was difficult for me to know exactly who was participating, especially if students had no pictures on the platform, and sometimes when they almost all talked at once it became quite unmanageable to handle questions and enquiries. Similarly, taking attendance was a bit challenging because I never knew who attended the entire class or only a few minutes before the end of it.

Technically speaking, there was one main problem related to internet connection where sometimes students' utterances or mine sounded like echoes, which affected the clarity of meaning, and hence we had to repeat them. This led to waste in class time, and hence shortened the time of the activity at hand.

Organizationally speaking, there was one rule I constantly stressed in terms of class organization and management. That is to say, if one participant, you or I, speaks, the others should turn off their microphones because there were times when I heard loud family communications coming from students' homes. Once we all agreed to do so, we proceeded beautifully.

With respect to examinations, it was striking that students were nervous and/or apprehensive as they already knew that the examinations were videotaped to be finally sent to the administration. This created an uncomfortable environment for students, as well as for me, particularly with concern to evaluation. As for videoconferenced lectures, they went very well and I should stress that they were labor-intensive due to the immense work-load and preparation. 
Toward the end of participant observation, I started to develop a high-precision realization that distance learning, in Morocco, is still in its embryonic stage. It has proven to be useful and can entirely replace face-to-face teaching in years to come. Yet, it has to be regulated, standardized, and most importantly systematically refined.

\subsubsection{Distance Learning Via WhatsApp}

WhatsApp, used for instant messaging where its users are able to exchange videos, audios, and texts, has become a vital learning platform during the current pandemic. With use and practice, WhatsApp has proven to be the most suitable application for my students. As a teacher of English, I started using it as a platform to flip some of my classes or share virtual lessons, follow-ups, and activities. Most of my classes were delivered in the afternoons due to the quarantine's side effects on students' sleep cycle. As a result, afternoon classes were adopted based on learners' request. The selection of this platform did not come to be by coincidence. I started delivering my digital content because the majority of my students could not afford other Apps due to the quick consumption of internet minutes. In case they could afford them, they may have lacked a device to use as many learners used their parents' devices, and oftentimes they missed a class because they lacked a digital device during virtual sessions. WhatsApp was seen as the most appropriate tool to opt for, for it is easy and quick to use. It is also a useful platform as it can allow the exchange of PowerPoint and PDF presentations, videos, audio content, and lessons that were shared on YouTube via links.

About 90 per cent of my students use WhatsApp on a regular basis because the majority were unable to recover their Massar's password. And since many of my students were either reluctant to use Zoom or could not afford it on their devices, we decided to keep the aforementioned App as the main platform for distance learning and was backed up by sending writing tasks and assignments to my official email address for correction and supervision. More importantly, the students who were very timid in traditional teaching showed a great deal of motivation. This took me by a pleasant surprise to discover this abrupt shift in the learners' attitudes performance. In fact, taking into account what damage could COVID-19 cause to their mental health and in an attempt to alleviate the side effects of this health crisis, I put students at the heart of the teaching/learning process where they felt free to express their perspectives. It was meant to enhance their learning, shape their autonomy, and tap on their multiple intelligences and learning styles. For this reason, I catered for a variety of virtual activities that could trigger their intrinsic and extrinsic motivation.

On the other hand, I could spot many defects of distance learning via WhatsApp. Having large classes, it was difficult to manage and respond to all students' questions, especially in reading, functions, and grammar. This active participation and willingness to ask or answer questions was more witnessed in face-to-face teaching. So, they kept asking the question "What about my task, teacher?" as soon as they read my interaction with some of their classmates. Thus, large classes in distance learning can create an organization issue, which requires effective training on the part of the teacher. Another challenge I faced was the fact that students were not all committed to their timed sessions or exercises, which led me to lengthen the session rather than respecting the time allotted to activities. This was very frustrating as it might have eaten up the time of the next class. Another issue that can potentially be discussed within this framework is when some of my students joined the group with a new name or pseudonym that I had never seen before in the group, it created an identity issue. In other words, I was not able to tell who was participating. This can be justified by learners' unreadiness to utilize this medium as an official platform for virtual learning. In brief, one lesson to draw from this participant observation is that distance learning has numerous positive points and limitations. As an EFL instructor, I should develop a constant self-awareness of any digital juncture that may creep in the education system. I 
should also keep reflecting upon my teaching practices in virtual classes to better understand my students and respond to their needs.

\subsection{Numerical Data}

In this section, we describe and analyze the charts provided below. The charts are based on the questions written in the questionnaire that is the primary means of data collection in the current research study.

\section{Fig. 1}

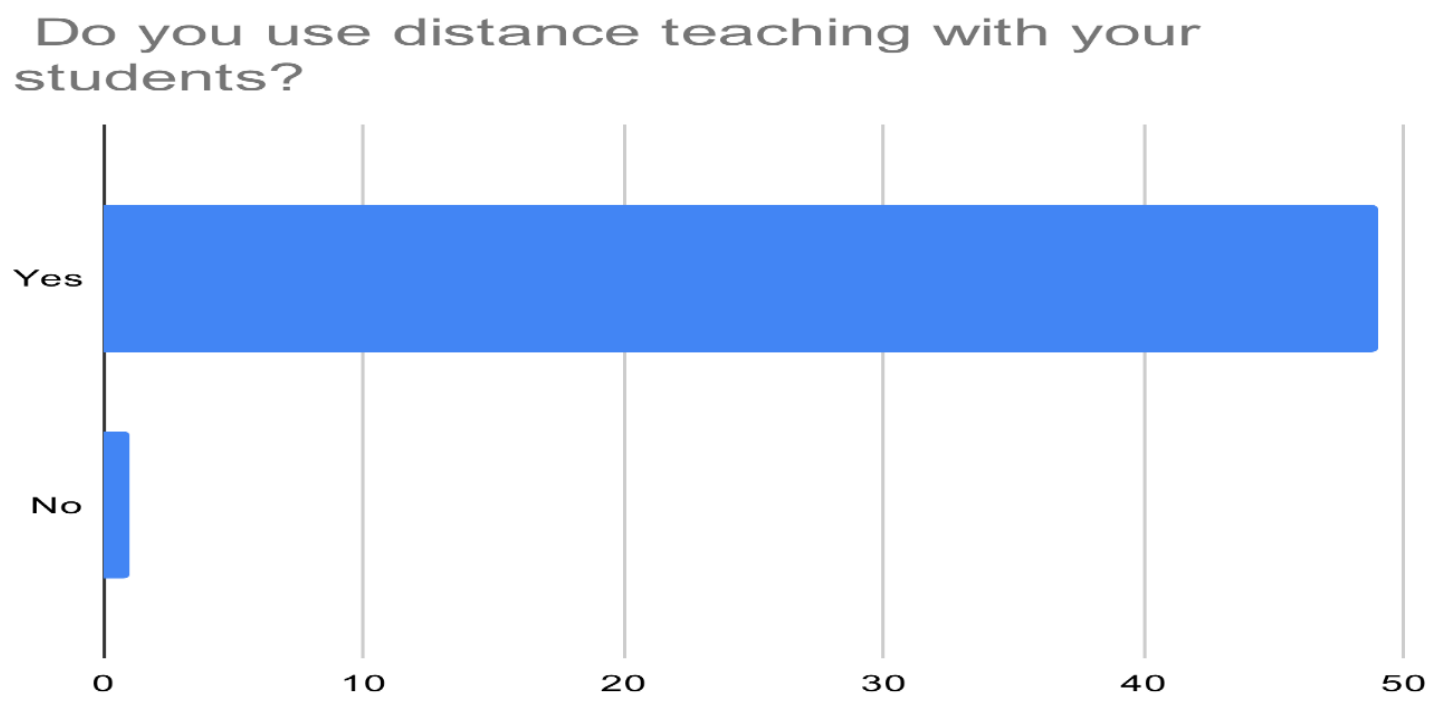

It is striking from the chart that $98 \%$ of participants use distance learning during COVID-19. This makes a lot of sense as the Ministry of National Education has consistently stressed on the use of different platforms and educational applications to facilitate the virtual transformation of classes. This transition has created a common learning space for students who live in different locations. This technological predisposition is remarkably meaningful and indicative of the rapid reception and implementation of distance learning. In fact, there would be no other way to save the current academic year from a doomed failure if there were no distance learning. School closures have forced many education systems to shift toward distance learning, which functioned as a harbinger of new practical teaching methodologies and practices, with a special focus on the teacher-student relationship and the dynamics that govern the EFL virtual classroom. One can almost express a conviction that distance learning for the majority of EFL instructors was an extraordinary opportunity to deepen and challenge their teaching skills and philosophy, and at the same time test their pedagogical endurance (class content, activities, and evaluation), by combining traditional teaching, blended learning, and flipped classroom all at once. This mixed-methods approach is most likely to bring about outstanding merits to the EFL instruction where students are exposed to diverse teaching styles. 


\section{Fig. 2}

What electronic device do you use?

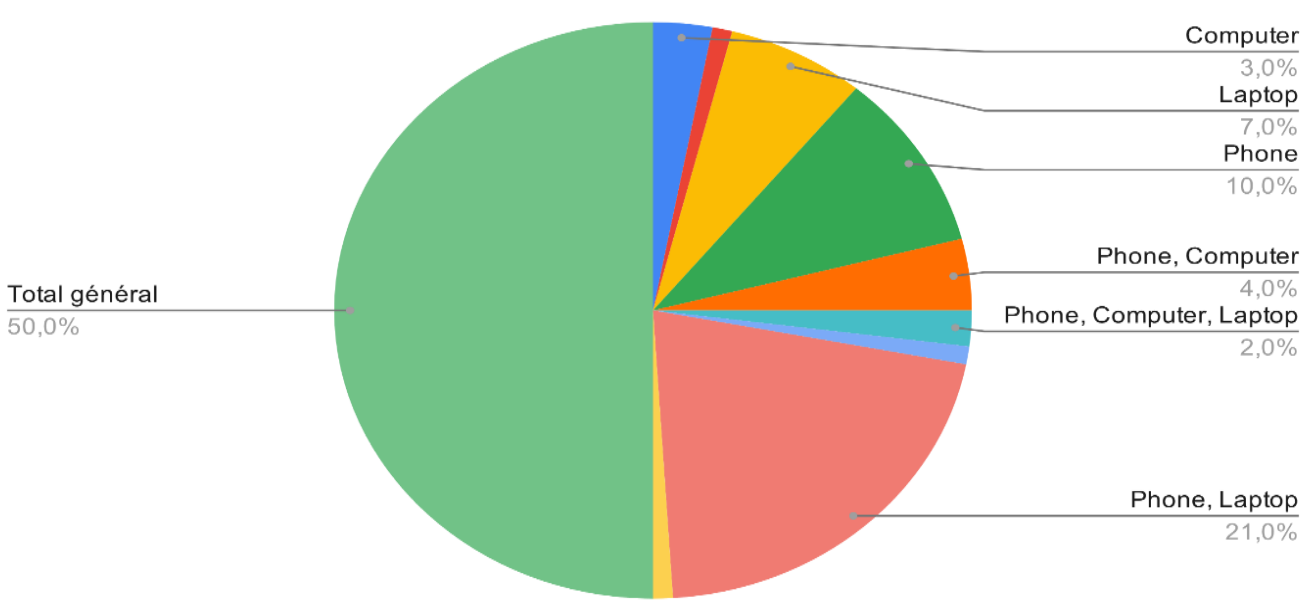

It is explicitly demonstrated that the vast majority of EFL instructors use their phones as an educational tool through which their courses get transmitted. The flexible use of phones and the rapid installing of applications have made this device gain traction in the field of education. Most teachers use this device to send instructions, lessons, videos, audios, and even grades. Through phones, the feedback is nearly always faster than any other communication device. In terms of costs, phones tend to be more affordable to students, and for this reason, teachers have opted to use their phones, while interacting digitally with them during COVID-19, mainly through WhatsApp and Facebook Messenger. Teachers know for a fact that a lot of students do not know how to use computers or laptops so as to download software and/or educational platforms (Moodle, Microsoft Teams, Google Classroom, etc.). In effect, the portability of phones makes the process of learning more free as both teachers and students can choose better connection spots or quiet and inspiring places in one's house. Laptops were also hugely used by teachers in this transition as their teaching materials have been kept on their desktops. The use of laptops enabled teachers to virtually teach, check, monitor, supervise, examine, and take attendance simultaneously, whereas the previous device would be less efficient and more time-consuming to instantaneously do all these tasks. Minimalistically speaking, one gets to perform a great number of tasks, and plus the battery life can sustain long hours of continuous work. It must be noted that distance learning demands the availability of laptops with good performance as there are times when the screen freezes unexpectedly, the system gets blocked, or the battery quickly dies. These mishaps commonly happen with low-performing computers. In the third rank, participants chose computers. This suggests that teachers worked in a specific place in the house (study room) that perhaps created more comfort for them. Similarly, it potentially suggests that they do not own a laptop for some reason. Conversely, there are fewer participants, according to the chart, who use the previously mentioned electronic devices all at once in distance learning, which could be useful for more interaction and research without leaving the platform page. This might engender a sense of confusion though. Indeed, having different communication devices might serve as plan B as one cannot always expect what to happen with technology. 
Fig. 3

\section{What online platforms do you use?}

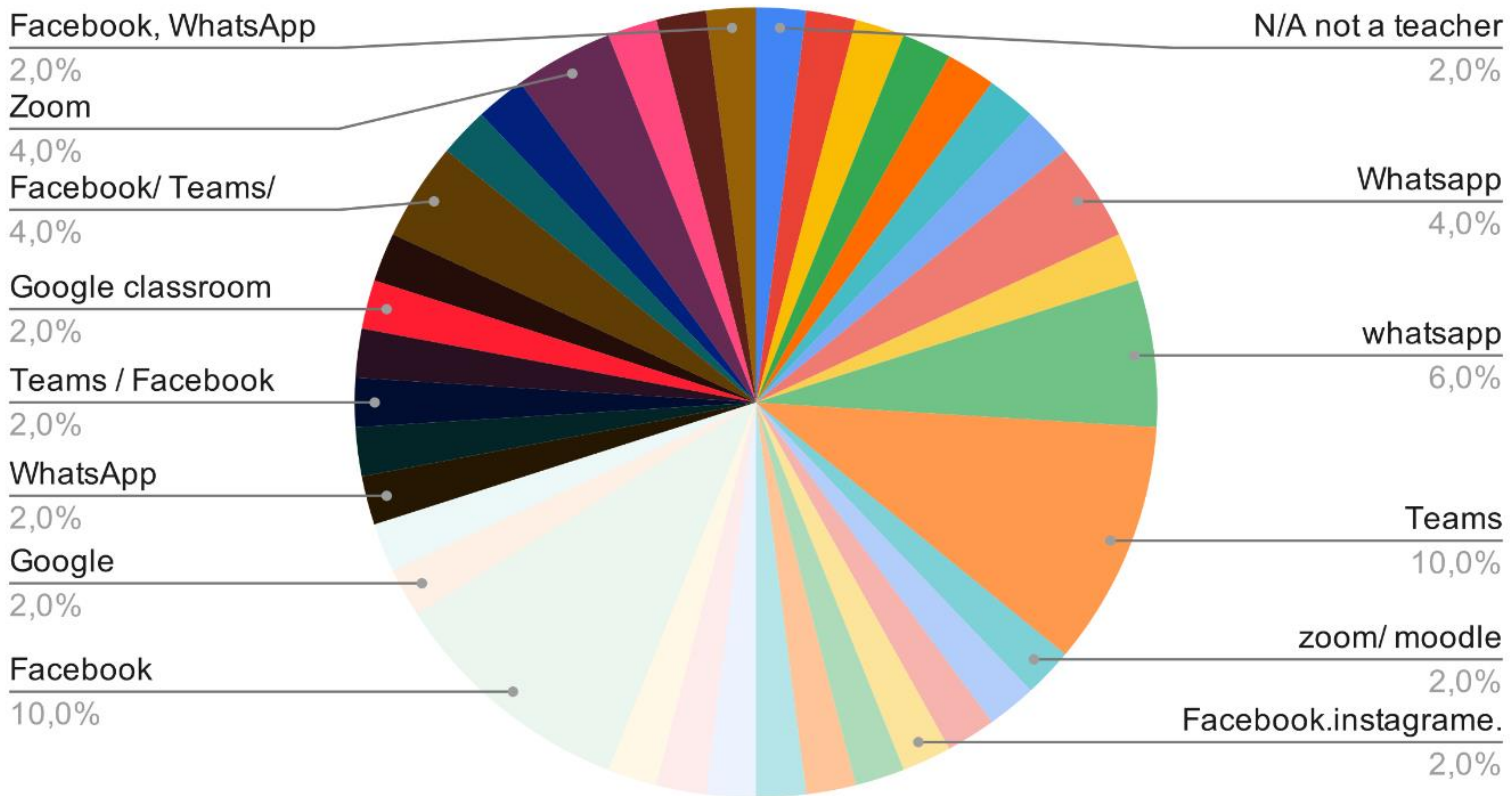

The data under analysis is provided through administering a questionnaire to $50 \mathrm{EFL}$ teachers and professors to investigate their attitudes and perceptions, while using distance learning, as well as to pinpoint the structural challenges they faced during this process. The pie chart above features the most extensively used platforms to deliver online lessons and activities, and the extent to which they were used. It is worth noticing that WhatsApp received the highest percentage. The second platform that was made use of is Facebook, followed by Microsoft Teams. In addition to that, the platforms Zoom and Google Classroom were equally used by 7 EFL teachers, which came before YouTube, while only $2 \%$ of participants used their school websites, Moodles, Meet, Gmail, Tamkin, Rosseta and Instagram. This data implies that most EFL teachers opted for the most common platforms they are already familiar with, namely WhatsApp and Facebook. Many teachers utilized WhatsApp since the latter is easy to use by both teachers and learners. In practice, they kept using WhatsApp because they feared moving from their comfort zone to a new one where they were supposed to learn about new apps and platforms. This preference is also explained in terms of the effects of the abrupt outbreak of Coronavirus, which left no room for the utilization of other applications. Moreover, many students could not afford to have other platforms on their devices due to internet consumption. Some participants used live streaming on Facebook or taught through Facebook's groups to deliver virtual content. Some were in favor of using Facebook due to two main reasons: The first is concerned with having large classes, hence teachers used it more than Zoom or other platforms. The second reason for using Facebook is that numerous teachers were skeptical about the digital safety of using Zoom since it operates via a shared link. The third prominent platform that was used is Microsoft Teams, which was officially recommended by the Moroccan Ministry of National Education and Vocational Training. Still, a big array of teachers could not use this platform either due to a lack of sufficient and effective training or the scarcity of access. Another fact that justifies teachers' unwillingness to prioritize the use of Microsoft Teams is by virtue of its technical nature, which demands at least familiarization. 
Fig.4

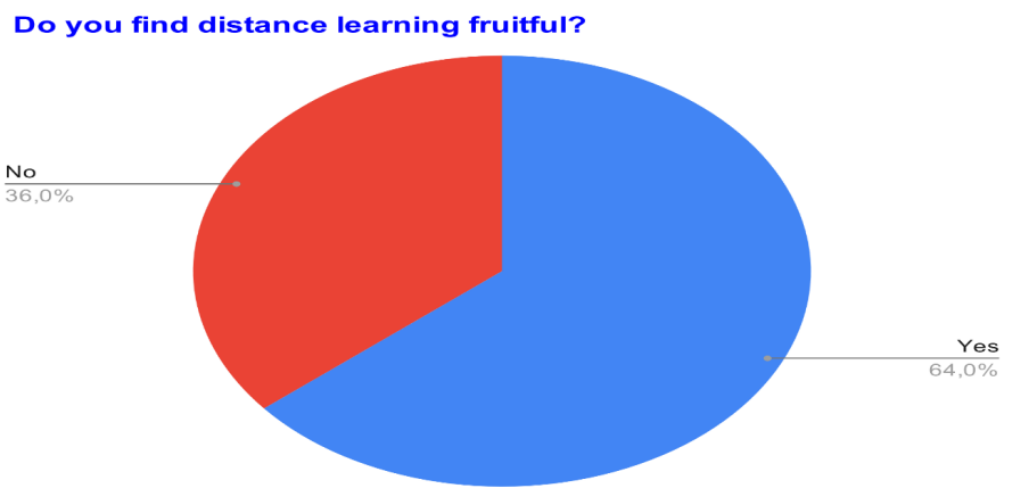

The chart above highlights the extent to which distance learning is profitable. It is remarkable that $64 \%$ of the participants stress its fruitfulness. This significant percentage is not a mere rate. Rather, it shows a constant predisposition toward distance teaching and the attempt to explore effective pedagogies and platforms for its success. In fact, distance learning is more fruitful than traditional teaching when it is regulated and properly operated as its merits can wholly radicalize the perception of education among educators and learners.

However, $36 \%$ of the participants see no benefits in distance learning. This attitude is not only triggered by their inability to cope with this new juncture in education after the outbreak of COVID-19, but also their incapability of continuously desingning diverse online materials to respond to different students' learning needs and styles. In reality, this new form of learning imposes many pedagogical and technological issues. Such issues can be overcome over time through training and practice.

\section{Fig. 5}

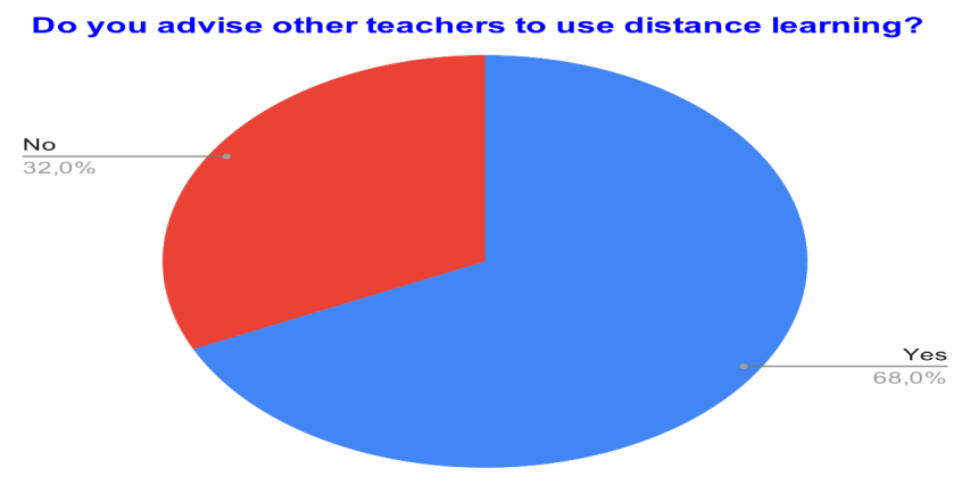

The above close-ended question displays a very interesting percentage of participants who favored the use of distance learning and advised others to use as well. The majority $(68 \%)$ highlighted the need for embracing distance learning because it benefits both learners and teachers. Teachers can improve professionally by getting used to delivering virtual content, online interaction with students, and training related to the development of ICT skills. Teachers can also foster their digital teaching practices and cater to a variety of engaging activities by putting learners at the heart of the teaching/learning process. When teachers emphasize learners' centrality, they prompt learners to develop metacognitive skills, such as critical thinking and problem solving, and most importantly create curiosity in them. 
Hence, it is important to embark on using both objective-centred approach and competencybased approach to benefit learners and keep them engaged.

Conversely, $32 \%$ of participants do not recommend using distance learning since it became an onus to them after the announcement of the emergency case in Morocco and the closure of all schools. Teachers were not digitally ready to deliver, monitor, and supervise virtual content. Second, their underprivileged students did not fully benefit from distance learning as they did not have access to either devices or internet connection. Third, distance learning largely created a gap among learners, particularly students in some remote rural areas where there is no electricity and internet infrastructure.

Fig. 6

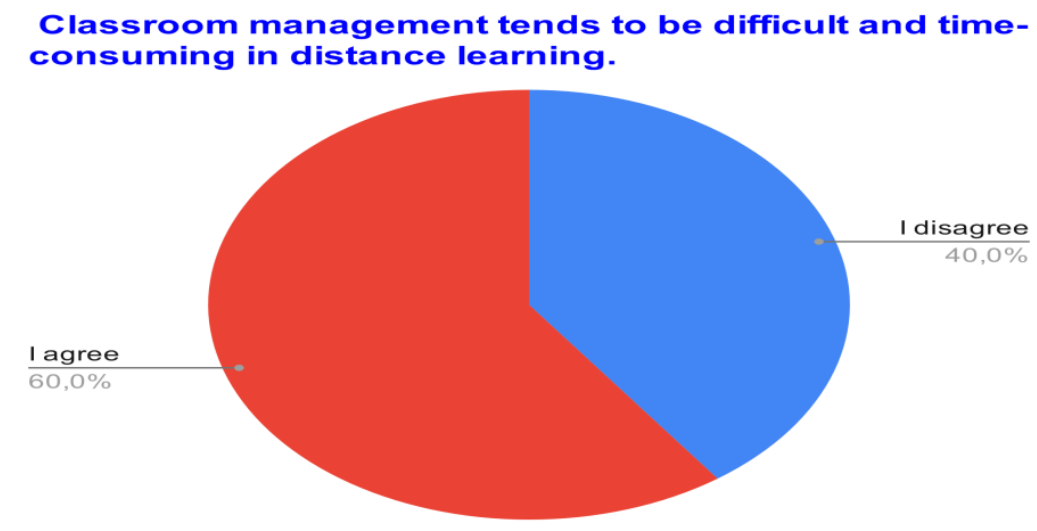

One of the markers of any course success, be it virtual or non-virtual, is a sound and seamless management. The latter allows the transfer of knowledge to happen in the most possible organized ways. This can affect various class components, such as attendance, participation, lesson planning, content development, pedagogy and evaluation. According to the above chart, $60 \%$ of participants agree that classroom management tends to be both difficult and time-consuming in distance learning. One should keep in mind that the Moroccan education system has never experienced any form of such learning before. It was strikingly the first time that Moroccan EFL teachers were exposed to distance learning, hence it would naturally be almost impossible to flawlessly adopt this approach. This requires a gradual development of online teaching skills and continuous course content modifications in order to meet the requirements of the curriculum in general, and the syllabus in particular. In fact, it can sometimes be difficult to deliver successfully organized class sessions, especially when many highly motivated students participate at once without respecting the instructions provided at the start of the activity. Furthermore, flexibility is required in every phase of distant learning implementation as teachers seem to enjoy little power, and their instrumental role in classroom management appears to be extremely weakened by students' commitment to distance learning, such as late virtual attendance or absence due to either internet access or connection. Real-time communication with students can often be against the pedagogical objectives of a certain course as most students erroneously consider distance learning as a platform for correspondence in lieu of online learning. This might lead to waste in-class time, which affects the flow and purpose of activities set in a particular class session.

The other $40 \%$ of participants who disagreed can possibly be explained in the fact that some EFL teachers were already familiar with software-based teaching, online games, and/or educational applications and platforms. But since there has been no impact assessment of distance learning by the Ministry of Education so far, we would not be at a fair position to truly evaluate the success/failure of classroom management in distance learning. 


\section{Fig. 7}

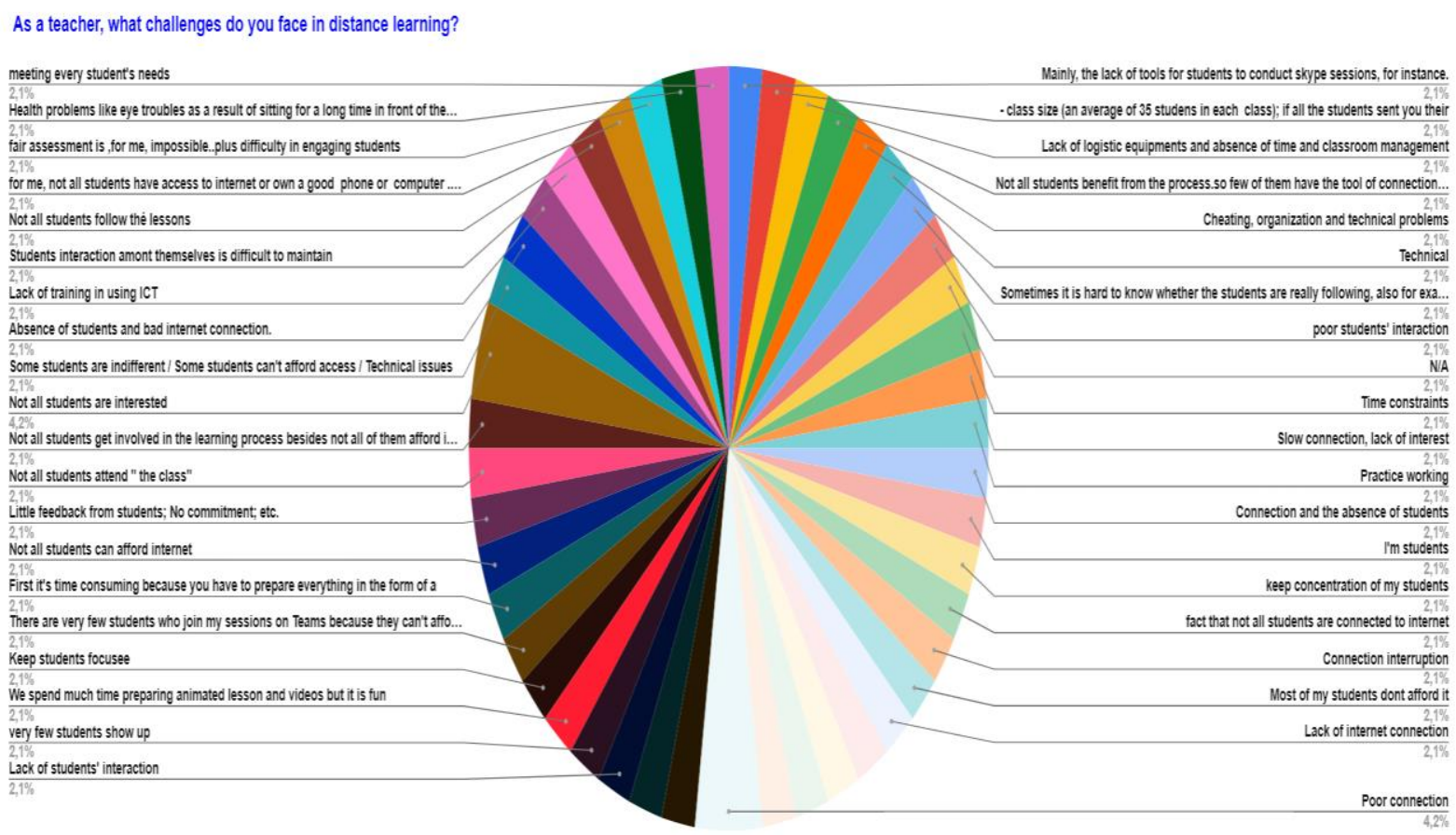

This chart encompasses a variety of responses concerning the challenges teachers face, while operating distance learning. The gathered data unveils the most prominent barriers in distance learning and online teaching. Most participants agreed that there is a managerial issue in distance learning because learners did not take this initiative to seriously maintain the continuity of the current academic year. Therefore, many students joined lessons or assignments' correction very late. By large, participants contend that distance learning is time-consuming and labor-intensive with respect to lesson planning and activities designed for different learning styles and multiple intelligences. Others stress that their inability to accommodate their students' needs and expectations is because they lack effective pedagogical training. More importantly, many participants confirm that they witnessed many challenges in teaching fluency-based activities. They claimed that students rarely managed to express their perspectives verbally, which means that there is a gap in the teaching methods and approaches apart from lacking other skills. Furthermore, poor internet connection, along with some technical issues were a real disruption that turned virtual lessons to a failure to a large extent. Given this, decision-makers are recommended to launch a sustainability plan to equip schools with digital tools, and offer effective training to teachers on ICT education. In doing so, they will empower teachers, who will be able to empower students to become digitally savvy and independent. 
Fig. 8

\section{How would you improve students' experience in distance learning?}

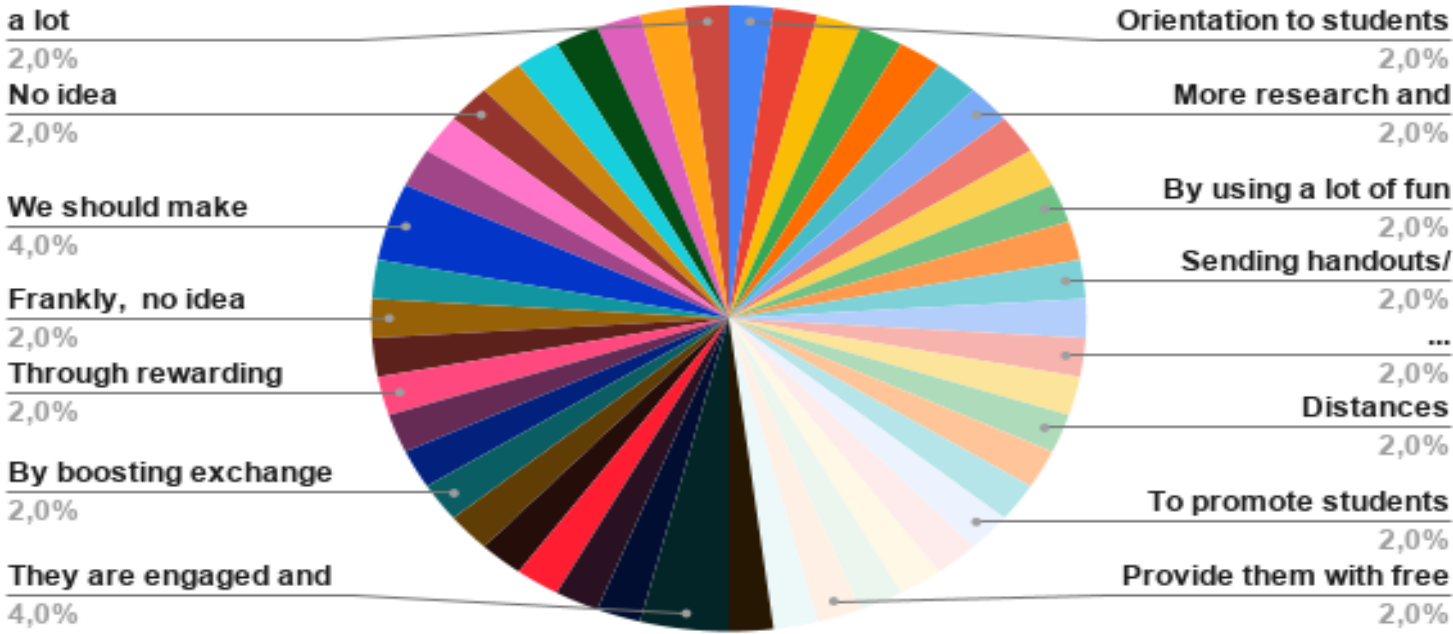

This chart incorporated an important open-ended question, which attempts to provide remedy to the increasingly mounting pressure of distance learning during COVID-19 on the EFL teachers. The majority of responses were positive, which reveals the readiness of teachers to adopt this new form of learning. There were many important repeated answers, such as research, training, and availability of electronic devices and internet access for both teachers and students. Apparently, these are the main pillars of distance learning implementation. Research and training will theoretically lay the foundation, whereas electronic devices and internet availability will concretize and complement the experience of virtual learning. The other recommendations were more premised upon the pedagogical roles that teachers have to take on in distance learning, such as assigning mini-projects, interactive and fun activities, and process-oriented content. As students learn to do online homework assignments and exercises, they will learn how to become more autonomous in their learning, especially when class activities are research-oriented.

In the same manner, testing should be done periodically in order to measure students' progress in the activities done in class. Participants emphasized that the teaching materials should be diverse, such as the inclusion of videos, songs, documentaries, and so on so as to make this online-based teaching more visually enticing and interesting. In order to boost students' intrinsic and extrinsic motivation, teachers should encourage students to use distance learning, give them a sense of achievement, praise their efforts, check on them constantly, have online office hours for struggling learners, show empathy, and so forth. All of these human qualities will be ultimately conducive to a far better reception and application of distance learning.

Other recommendations were made with respect to making distance learning part of our everyday teaching, as well as properly handling the impediments witnessed in the actual experience. There should also be an online application that keeps track of students' attendance and participation. In a nutshell, if all of the abovementioned recommendations are thoughtfully implemented, we will be empowered to regulate and refine distance learning in Morocco. 


\section{CONCLUSION}

The current study investigated the EFL instruction in the wake of COVID-19. It principally emphasized teacher's attitudes, while underlining the major challenges they digitally and pedagogically encounter. In fact, this study sought to ferret out the affective factors witnessed in the process of the distance learning application. According to the results obtained by means of questionnaire and participant observation, it is crystal clear that distance learning is still making 'baby steps', in Morocco, as it is faced with numerous structural problems ranging from infrastructure and pedagogy to content and evaluation. Likewise, EFL teachers showed a great deal of interest in distance learning. This readiness will ipso facto pave the way for more regulated procedures to take place in order to maximize access to ICTs in order to refine and standardize distance learning in our education system. It was also found out that distance learning was generally a positive experience for both teachers and students as it had the potentiality to change the EFL classroom dynamics for the better, particularly through the use of videos, games, and software-based learning. Thus, learning by doing is manifested through the use of different types of activities where learning styles are fostered and motivation is triggered. This learning method unquestionably encourages students to become more autonomous and sustainable as there is no use for photocopying and/or printing. Furthermore, it will radically change the way we look at education, mainly teachers' roles in the classroom.

The flexibility, geographical difference, and sustainability that distance learning offers urge decision-makers, curriculum designers, and EFL instructors to reconsider their educational approach and philosophy as the dynamics are not the same anymore. It is almost unheard of that a certain approach/method delivers $100 \%$ successful results and/or bring about a magical solution that impeccably fits into the EFL community. Obviously, there were a few mishaps, such as low-resourced areas, poor internet connection, mediocre sound quality (echoes), scarcity of communication devices for some students, and so forth. However, these mishaps should not discourage us and can be gradually surmounted over time, provided that decision-makers are willing to embrace change and strive to promote professional development in order to enhance the framework of digital literacy in the English language instruction.

\subsection{Further Work}

Future studies should investigate multimedia-based content, pedagogy, evaluation, and teachers' professional training in distance learning. These are extremely important elements in the realm of teaching. The findings yielded by these studies will exponentially invigorate the interaction between teachers and students in the EFL instruction to optimize productivity.

Since distance learning is still in its embryonic stage, it requires more empirical research so as to be in a better position to evaluate it, since there has not been yet any authentic impact assessment conducted by the Ministry of National Education and Vocational Training. Such assessment should be appropriate to our Moroccan context in order to make firmer conclusions that will be eventually conducive to a more regulated distance learning implementation.

Funding This study was not funded in any shape or form by any party.

Conflict of interest The authors declare that they have no conflict of interest. 


\section{REFERENCES}

Becta (2004). What the research says about portable ICT devices in teaching \& learning. London: British Educational Communications and Technology Agency.

Belanger, F., \& Jordan, H. (2000). Evaluation and Implementation of Distance Learning: Technologies, Tools and Techniques. London: Ideal Group Publishing.

Bouziane, A. (2019). ELT issues in Morocco: A research-based perspective (pp.137-149). MATE ELT series: Book 4. Moroccan Association of Teachers of English (MATE).

Brand, G. (1998). What research says: Training teachers for using technology. Journal of Staff Development, 19(1), 10-13.

GENIE Directorate. (2012). Programme GENIE: Guide de Formateur. Module PDPTICE 2012. MEN.

Harris, J., Mishra, P., \& Koehler, M. (2009). Teachers' technological pedagogical content knowledge and learning activity types: Curriculum-based technology integration reframed. Journal of Research on Technology in Education, 41(4), 393-416.

Hutchison, A., \& Reinking, D. (2011). Teachers' perceptions of integrating information and communication technologies into literacy instruction: A national survey in the United States (pp.312-333). Reading Research Quarterly.

Jones, A. (2004). A Review of the Research Literature on Barriers to the Uptake of ICT by Teachers. UK: Becta.

Kirkpatrick, D. L., \& Kirkpatrick, J. (2006). Evaluating training programs: The four levels. Williston: BerrettKoehler.

Kirkwood, A. (2008). Getting it from the Web: Why and how online resources are used by independent undergraduate learners. Journal of Computer Assisted Learning, 24(5), 372-382.

Mumtaz, S. (2000). Factors affecting teachers' use of information and communications technology: A review of the literature. Journal of Information Technology for Teacher Education, 9(3), 319-341.

Nachit, B., Tamani, S., Radid, M., Namir, A., \& Talbi, M. (2013). Mathematics teachers' participation in Innovative teacher's contest in Morocco. International Journal of Research In Education Methodology, 4(1), 372-381.

Online document Mots du Ministre Missions Textes Juridiques (2000). Plan Quinquennal Projets Manifestations Contacts Liens Forum home. United Nations Economic Commission for Africa (UNECA).

Picciano, A. G. (2017). Theories and frameworks for online education: Seeking an integrated model.

Online Learning, 21(3), 166-190.Sadeghi, H. (2019). Training in cyberspace. In: Pathology of Learning in Cyber Space. Studies in Systems, Decision and Control. New York: Springer Berlin Heidelberg.

Simin, G. et al. (2016). Teaching and learning with ICT tools: Issues and Challenges from Teachers' Perceptions. Malaysian Online Journal of Educational Technology, 4(2), 38-57.

\section{AUTHORS'BIO}

${ }^{1}$ Bachiri Housseine is an Assistant Professor at the Euromed University of Fes. He earned his PhD in 2017 in Applied Linguistics and Education. He has been teaching English as a foreign language for several years. His research interests are language teaching, pedagogy, ICTs, and curriculum design.

${ }^{2}$ Sahli Rabha is a high school teacher. She is also a PhD student at Ibn Tofail University in Kenitra, Morocco. She has been teaching English to high school students for many years. She is fond of research on ICT, innovative teaching methods, English composition, and so forth. 